\title{
Dynamic simulation testing of transformer protection based on ADPSS
}

\author{
Jinli Xiao ${ }^{1, a^{*}}$, Ruiming Fang ${ }^{1, b}$ \\ ${ }^{1}$ College of information science and engineering, Huaqiao University, Xiamen 361000, China \\ an6@163.com, ${ }^{b}$ fangrm@126.com
}

Keywords: ADPSS; ETSDAC; Transformer protection; dynamic simulation test; inter-turn short circuit.

\begin{abstract}
This paper presents a dynamic simulation test method of transformer protection based on Advanced Digital Power System Simulator, ADPSS. Firstly, a simulation model of three-phase three-winding transformer has been proposed in ETSDAC, a commercial electromagnetic transient simulation program. Then, according to the Chinese national standard rules, 3 modeling schemes of dynamic simulation, including inter-turn short circuit, internal metal fault of differential protection, and recovery inrush, have been designed to simulate the running situations of the transformer under various conditions. The simulation results show that the proposed method has an important referential significance for the failure analysis of transformer.
\end{abstract}

\section{Introduction}

With the development of power system dynamic simulation technology, a large number of the scientific research and test work have been accomplished by means of dynamic models [1-4]. The dynamic model simulation makes a comprehensive test of the function and the overall performance of the device, and it has great advantages in the principle research of transformer protection. At present, there are many power system digital simulation systems. Among them, Advanced Digital Power System Simulator (ADPSS) is developed by China Electric Power Research Institute. ADPSS uses the electromagnetic transient program, which can be used to establish the system model and solve the problem of power system calculation, such as fault analysis, fault or operation of the power system, and meet the needs of the users for power system simulation analysis.

In this paper, in order to carry out the simulation test of transformer protection based on ADPSS, we take $220 \mathrm{kV}$ three-phase three-winding transformer for example. According to Chinese national standard rules requirements of GBT 26864-2011 [5], 3 fault models are built, including inter-turn short circuit, internal metal fault of differential protection, and recovery inrush. The simulation results show that the model can meet the requirements of the transformer protection test.

\section{Dynamic simulation modeling of transformer protection}

A typical connection mode and basic requirements of the transformer protection dynamic model test are given in [5]. In this paper, three-phase three-winding transformer model is studied and the dynamic model test is simulated in $220 \mathrm{kV}$ system. Fig. 1 is the wiring diagram of the transformer protection test, $\mathrm{K} 1-\mathrm{K} 8$ are the fault points.

ETSDAC is the software of the independent development of the Chinese Electric Power Research Institute, it has a large number of electromagnetic transient element model, which can simulate the power system conventional components and a variety of common failure modes. In ETSDAC, a three-phase three-winding transformer element model is provided, which is composed of three single-phase three-winding transformers. In simulation calculation, the transformer model is represented by the R-L coupling branch, and the equivalent circuit is shown in Fig. 2.

In Fig. 2, $T_{k 1}, T_{k 2}, T_{k 3}$ are 1, 2, 3 windings per unit ratio, $R_{1}, X_{1}, R_{2}, X_{2}, R_{3}, X_{3}$ are the 1,2,3 windings resistance and leakage reactance, $\mathrm{R}_{\mathrm{m}}, \mathrm{X}_{\mathrm{m}}$ are transformer magnetizing branch resistance and reactance. 


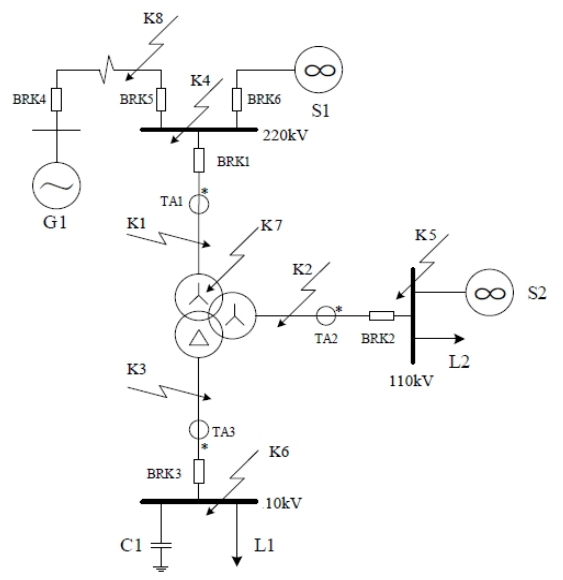

Fig. 1 Wiring diagram of $220 \mathrm{kV}$

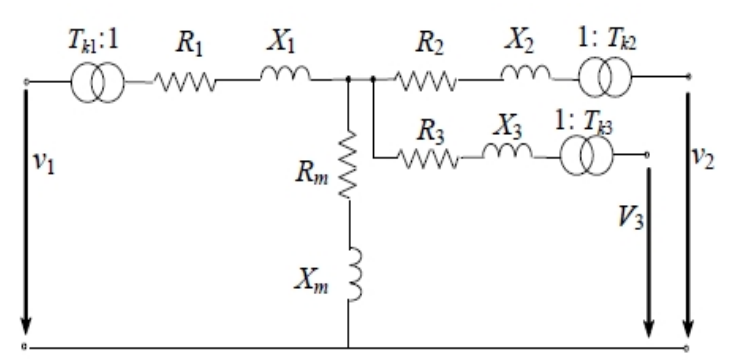

Fig. 2 Equivalent circuit of single-phase transformer three-phase three-winding transformer

In ETSDAC, three-phase three-winding transformer is composed of three single-phase three-winding transformers. When the inter-turn short circuit happens, short-circuited winding and the not short-circuited winding are considered as two separate windings, so the three-winding transformer is equivalent to four-winding transformer. The model is encapsulated in ETSDAC system as the following. The user defined model(UDM) module is inserted in the main program, three-phase three-winding transformer equivalent circuit is built in the module, as shown in Fig. 3, three-phase three-winding transformer is composed of three sub-circuits. Then, A single-phase three-winding transformer is built in each sub-circuit, as shown in Fig. 4, which is the sub-circuit of the inter-turn short circuit.

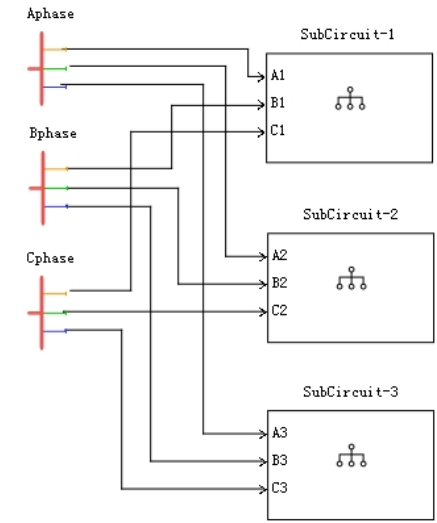

Fig. 3 Equivalent circuit of three-phase three-winding transformer

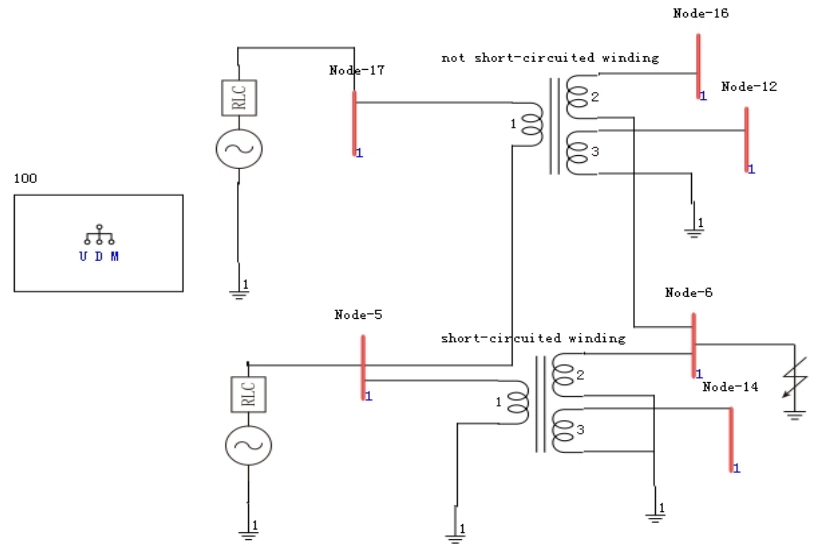

Fig. 4 Wiring diagram of single-phase three-winding transformer inter-turn short circuit

\section{Inter-turn short circuit test}

In the test, the turns of the inter-turn is $1 / 10$ of the total turns. Fault lasting time is $0.05 \mathrm{~s}$, the simulation time is $0.1 \mathrm{~s}$. The three-phase voltage waveform of the middle voltage of the inter-turn short circuit is shown in Fig. 5.

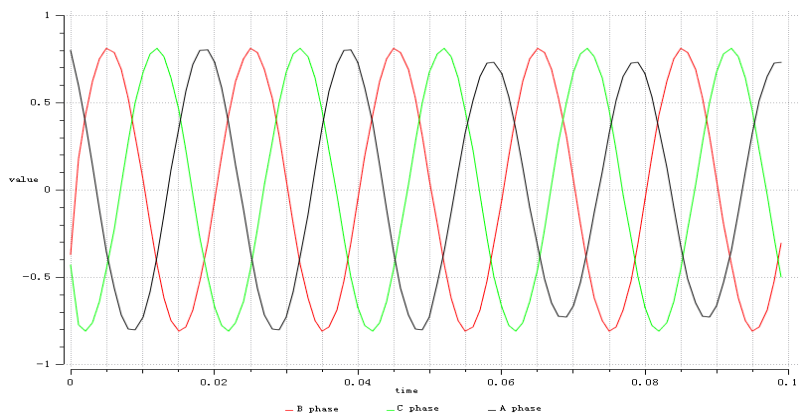

Fig. 5 Three-phase voltage waveform of the inter-turn short circuit with ETSDAC 


\section{Dynamic simulation test}

In order to carry out the transformer protection test, 3 modeling schemes of dynamic simulation, including inter-turn short circuit, internal metal fault of differential protection, short-circuit through the transition resistance, developing fault and recovery inrush, are tested by changing the fault location, fault duration, grounding resistance, fault type and control circuit breaker.The simulation system is shown in Fig. 1. The main parameters are as follows:

System base capacity is 100MVA.

Transformer parameters: ratio is $220 \mathrm{kV} / 110 \mathrm{kV} / 10.5 \mathrm{kV}$, connection mode is $\mathrm{Yg} / \mathrm{Yg} / \mathrm{D} 11$, $\mathrm{P}_{12}=449.76 \mathrm{~kW}, \triangle \mathrm{P}_{23}=102.57 \mathrm{~kW}, \triangle \mathrm{P}_{31}=136.88 \mathrm{~kW}, \mathrm{~V}_{12} \%=13.06 \%, \mathrm{~V}_{23} \%=7.85 \%, \mathrm{~V}_{31} \%=22.85 \%$, $\mathrm{P}_{0}=113.51 \mathrm{~kW}, \mathrm{I}_{0} \%=0.17 \%$.

Generating set parameters: $P_{n}=125 \mathrm{MW}, X_{d}=1.867 p u, X_{d}^{\prime}=0.257 p u, X_{d}=0.18 p u, X_{q}=1.867 p u$, $\mathrm{X}_{\mathrm{q}}{ }^{\prime}=0.385 \mathrm{pu}, \mathrm{X}_{\mathrm{q}}{ }^{\prime \prime}=0.18 \mathrm{pu}, \mathrm{U}_{\mathrm{n}}=10.5 \mathrm{kV}, \mathrm{S}_{\mathrm{n}}=150 \mathrm{MVA}$.

Line parameter : $\mathrm{R}_{1}=0.054 \Omega / \mathrm{km}, \mathrm{R}_{0}=0.162 \Omega / \mathrm{km}, \mathrm{X}_{1}=0.000981 \mathrm{H} / \mathrm{km}, \mathrm{X}_{0}=0.002943 \mathrm{H} / \mathrm{km}$, $\mathrm{C} / 2=0.0058 \mathrm{uF} / \mathrm{km}, \mathrm{L}=104.54 \mathrm{~km}$.

The inter-turn short circuit model of the three-phase three-winding transformer is established in the test. The occurrence of high voltage side winding inter-turn short circuit is simulated in the full-load transformer. The fault time is $10 \mathrm{~s}$, and $\mathrm{K} 7$ is set to inter- turn short circuit fault, respectively. The short circuit turns (the ratio of the total turns) is simulated in $2 \%, 5 \%$ and $10 \%$, respectively. High voltage side output voltage waveform is shown in Fig. 6, the output voltage value is shown in Table1.

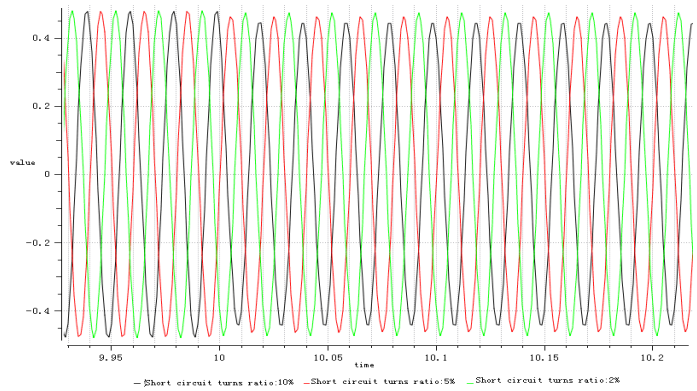

Fig. 6 Output voltage waveform of inter-turn short circuit

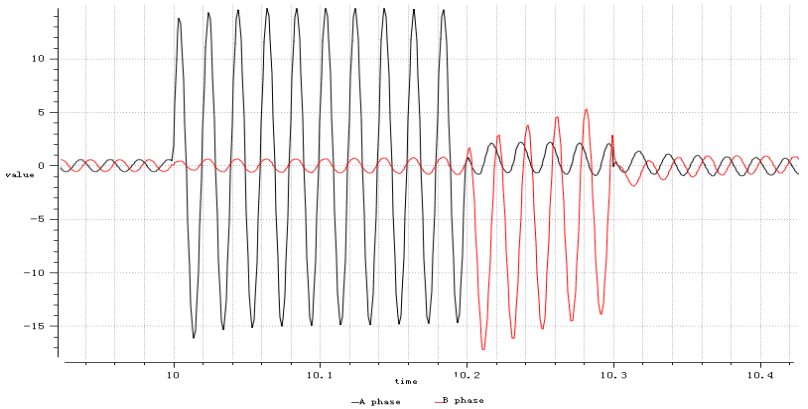

Fig. 7 Current waveform diagram of single-phase to ground fault

Table.1 Comparison of the output voltage value of the short circuit turns ratio

\begin{tabular}{llll}
\hline $\begin{array}{l}\text { Short circuit } \\
\text { turns ratio/\% }\end{array}$ & $\begin{array}{l}\text { Pre fault voltage } \\
/ \mathrm{pu}\end{array}$ & $\begin{array}{l}\text { Post fault voltage } \\
/ \mathrm{pu}\end{array}$ & $\begin{array}{l}\text { Voltage change } \\
\text { rate } / \%\end{array}$ \\
\hline 2 & 0.480 & 0.474 & -1.25 \\
5 & 0.480 & 0.463 & -3.50 \\
10 & 0.480 & 0.441 & -8.13 \\
\hline
\end{tabular}

The single phase to ground fault is simulated in full-load transformer in the case of high voltage side. Set the single-phase fault components in $\mathrm{K} 1$ and $\mathrm{K} 4$, respectively. A phase ground falut is set in K1, the fault time is $10 \mathrm{~s}$, the failure duration is $0.2 \mathrm{~s}$, B phase ground falut is set in $\mathrm{K} 4$, the fault time is $10.2 \mathrm{~s}$, the failure duration is $0.1 \mathrm{~s}$. The fault current of the high voltage side output is shown in Fig. 7. The differential current setting value of the protection device of the system is $6 \mathrm{I}_{e}$, and it can be obtained from the curve of the short-circuit fault in the differential protection zone, which the short circuit circuit is far greater than the system setting value, so the protection device action normal.

Before recovery inrush current test, the transformer model should meet a sufficiently large current in the dropping, which should be not less than 2 times the rated current peak. In practical power system, it is difficult to observe the recovery inrush current directly from one side of the transformer when the fault is removed [6]. Therefore, it is of great value to study the modeling of recovery inrush current.

In the test, The circuit breaker of medium voltage side(near the power side) action, breaking time is $10 \mathrm{~s}$, reclosing time is $10.5 \mathrm{~s}$. The three-phase current waveform of the middle voltage side is shown in Fig. 8 . 


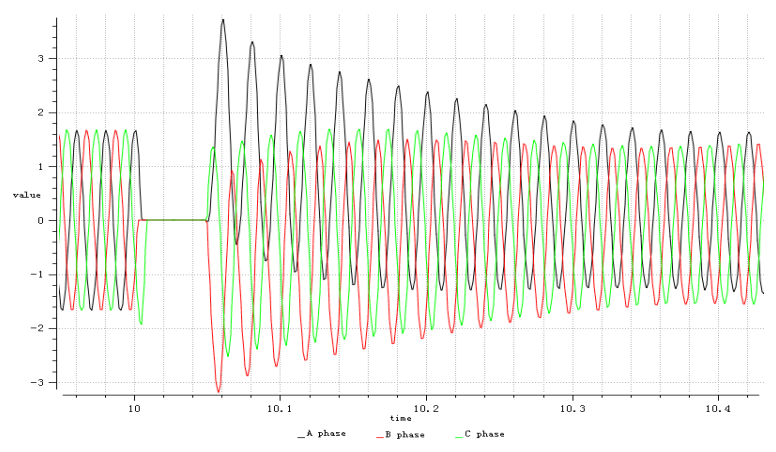

Fig. 8 No-load transformer current waveform

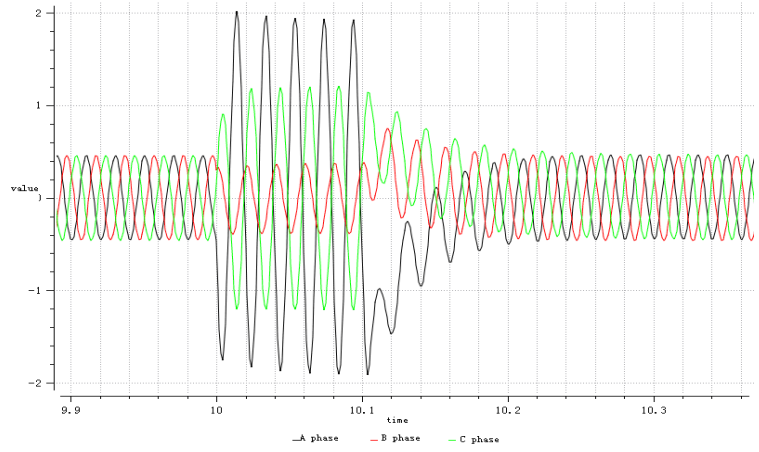

Fig. 9 Waveform of recovery inrush current

From the test, the maximum peak current value is 3.812pu in side A of A phase, and the maximum current peak at normal operation is $1.675 \mathrm{pu}$, which meets the requirements of the standard.

Then the recovery inrush current test is simulated. The whole process of the system has experienced three operating conditions, inculding normal operation, the area of failure and fault removal. The fault element is set in K8, the fault mode is A-phase ground fault, the fault time is 10s, and the fault duration is $0.1 \mathrm{~s}$. When the fault disapperars and the current zero clearance, the fault clears. The three-phase current waveforms of the high voltage side are shown in Fig. 9.

\section{Conclusions}

This paper presents the inter-turn short circuit model, which is built by UDM function of ETSDAC. It is shown the model is suitable for the transformer protection test. In the transformer protection test project, the relevant fault can be set up conveniently according to the requirement of the standard rules, and the fault simulation waveform can be clearly demonstrated by the operation characteristics of the transformer protection system in various working conditions, and it can help to carry out the further research on the test of transformer protection.

\section{Acknowledgements}

This work was financially supported by Xiamen major scientific and technological innovation platform project (3502Z2011008).

\section{References}

[1] Hongbin Zhang, Qiyu Liu, Yingmei Liu, Power System Technology. 2011, 35(1): 96-99(In Chinese).

[2] Chunxia Zhou, Rongrong Zhan, Jianning Jiang, et al. Power System Technology. 2010, 34(10): 90-92(In Chinese).

[3] Yong Tang, Yonghua Yin, et al. Multi scale simulation and testing technology of power system. China Electric Power Press, 2012(In Chinese).

[4] Dexian Yang, Deshu Chen, Fengge Zhang, et al. Power System Protection and Control. 2010, 38(9): 118-121, 125(In Chinese).

[5] GB/T 26864-2011, The dynamic test of the power system protective products.

[6] Kun Qian, Ming Xu, Lehua Shi. Transformer. 2013(12): 29-33(In Chinese). 